\title{
AzUsa Katagiri
}

\section{Opportunistic Violation in Crisis:}

\author{
A Test of Alliance Termination
}

The question of alliance termination raises a variety of theoretical and empirical issues in the study of alliances: Why do states abandon security agreements that they once welcomed? Under what conditions do states violate them? To answer these empirical questions, it is imperative to focus on individual states as the unit of analysis for further investigation of state behavior in given international security and domestic contexts. This article, which employs the "state approach," aims to offer insight into alliance violation. It relies on the Alliance Treaty Obligation and Provisions (ATOP) dataset and uses a competing-risks event-history model for estimating the risks of other termination modes, as in LeEDS and SAVUN (2007). This study primarily reveals that states opportunistically violate alliances at a higher level of external threats, in some cases for their own survival, or in others for their aggressive policies.

KEYWORDS: Alliance termination, capability aggregation model, interstate crisis

Azusa Katagiri is a postdoctoral fellow in the Weatherhead Center for International Affairs at Harvard University. This article is based on his master's thesis submitted to New York University in August, 2008. 
Alliance termination is a theoretical and empirical concern for the study of alliances. Beyond the problem of alliance durability and dissolution, it is also relevant to the study of alliance dynamics and states' alliance policies in a changing security environment. Most theoretical scholars, however, have tended to overlook this issue, despite the voluminous literature on alliance formation and reliability. ${ }^{1}$ One of the reasons for this seeming disinterest may be ascribed to less enthusiasm for "the final phase of alliance," in contrast to the discussion on formation and reliability, which has attracted significant attention both from the theoretical and policy sides. Additionally, the capability aggregation model (hereafter, CAM) promulgated by realists and neorealists has long shaped the conventional and prevalent view of alliance termination.

In response, previous scholarship on alliance duration and cohesion has revealed the limitations of CAM and its accumulated implicative findings. For example, Morrow (1991) provided an alternative model which related the durability of alliances to asymmetry and capability change and also tested the security-autonomy tradeoff model (Morrow 1993). BENNETT (1997) conducted comprehensive empirical tests on the existing hypotheses of alliance durability and obtained results that were inconsistent with CAM. Similarly, LeEDS and SAVUn (2007) estimated the impact of institutional aspects of bilateral alliance cohesion, which showed only weak support for CAM. Consequently, although CAM is the starting point for realists, the literature suggests that additional inquiry into the matter is required.

Thus, the question of how to relate alliance break-ups and external security conditions that states confront in a given international environment naturally arises. In other words, there are still merits in providing convincing answers to this question, which CAM was unable to do. Thus, the main objective of this paper is to explore how external security and threat factors drive alliance dissolution. Additionally, the study replicates previous work on other pertinent determinants of alliance termination.

Before explicating the approach to this article, I will discuss what makes the study of alliance termination methodologically challenging and often overlooked by IR scholars, which will make the reasons behind my approach more tractable. First, defining alliance termination in a clear-cut

1. There are numerous works on alliance formation and reliability. See, for example, Altfeld (1984), Altfeld and Bueno de Mesquita (1979), Bueno de Mesquita (1981), Bueno de Mesquita and lalman (1992), Fearon (1997), Holsti (1973), Lake (1999), Lalman and Newman (1991), Leeds (2003), Morrow (1994), Snyder (1997), Smith (1995; 1996; 1998), WALt (1987), and WALtz (1979). 
way and identifying each termination case is a demanding task. Theoretically speaking, I could define alliance termination both when a formal alliance pact expires (de jure), and when a mutual confidence or the cooperative relationship among member states in an alliance (de facto) collapses even if there is some time remaining until fulfillment. ${ }^{2}$ Although the latter way might be preferred with respect to assessing the relationship between alliance termination and changes to the security environment, the identification of de facto end dates for all such alliances is almost impossible.

Second, the mode of termination varies from case to case and is shaped by different causal processes. For instance, termination by violation is mostly the result of active decision-making by the "violating" state, while fulfillment may be classified as a more passive way of termination among states because they just wait until it expires. To address this methodological difficulty, LeEDs et al. (2002) coded various modes of termination (i.e., the Alliance Treaty Obligation and Provisions [aтор] dataset), which engendered more refined categories.

Third, the unit of analysis is a controversial issue. The conventional approach in recent work is to treat an alliance as an aggregated unit to better observe alliance cohesion. Although there is some merit to this "alliance approach," it inevitably lacks perspective on individual states' alignment behavior. Except for cases of involuntary alliance break-up, the state itself has the final say in terms of maintaining the alliance (or not). On a related note, differences in alliance size can affect-and even underminemore systematic approaches to alliance termination, because the processes that impel multilateral and bilateral alliances to termination are expected to differ from one other. While this article will further elaborate on these methodological difficulties, when necessary, their amelioration is beyond the scope of this article and will be reserved for future work.

The review of methodological challenges thus far, however, provides insights into how impediments to comprehensive research, at first glance, may be repurposed to achieve propitious ends. Specifically, by narrowing my focus to alliance "violators," rather than alliances themselves, this article will evaluate the relationship between alliance violation and security level/external threats in a given international environment.

Of course, this approach is not perfect. Leeds and SAvUn (2007) conducted empirical tests using only bilateral alliances as the units of analysis because they acknowledged the difficulty in identifying violators

2. The process leading the Soviet-China mutual defense treaty (1950-1980) to fulfillment clearly illustrates a time lag between its de facto and de jure terminations. 
for all alliance cases (LEEDS and SAVUN 2007, 1125). However, it is feasible for most of the violation cases; for example, violators in over $70 \%$ of the violation cases in the European alliances from the ATOP dataset are easily identifiable, which I will elaborate upon later. ${ }^{3}$ On the other hand, for the ambiguous violation cases, all the responsible violators are coded as violators because those cases are treated as violations by all the responsible parties (i.e., these cases are accompanied by exchanges of denouncements). The "violator approach" is a major innovation of this article and enables me to address crucial questions effectively, which CAM and the previous literature, for the most part, have not, such as "Why do states abandon security agreements that they once welcomed?" and "Under what conditions do states violate them?" Moreover, the narrower focus on violators will permit pooled estimation and allow me to consider both bilateral and multilateral alliances, since violators can be identified and their actions are consequential. Since this article uses a competing-risks event-history model for estimating the "risks" (of failure) of each of the termination modes, following LEEDS and SAVUN (2007), all the possible risks, not just those for potential violators, will be given adequate treatment.

This study reveals the following: first, the statistical findings, which are significant, contradict the predictions of the capability aggregation model, regardless of whether I consider a bilateral or multilateral context. Furthermore, it discusses these findings in light of the suggestion that, in some cases, states opportunistically violate alliances at a higher level of external threats for their own survival, or in other cases, for their aggressive policies. Second, it finds that the effect of domestic politics on a state's alliance violation is not as salient as external security and national capability factors. Third, the article shows that wartime alliances are short-lived, which is consistent with our intuition, but their termination by violation occurs less frequently than other termination modes. This is because the casus foederis clearly exists for the allies, and, as such, they have less incentive to deviate from a given agreement during wartime.

The remainder of the paper is organized as follows. The second section briefly reviews the relevant literature on alliance termination/violation and generates pertinent hypotheses therein. The following section, which discusses methodological difficulties in the study of alliance termination,

3. See, for instance, the Defense Pact between the UssR and Japan (1941-1945). I classified all members as violators, even for the obscure cases, such as the renunciation(s) by the Eastern European bloc after Yugoslavia's break with the UssR under Tito in 1949, as well as the agreements between the United Kingdom and the USSR (1941-1952). 
as outlined above, presents a research design and description of population samples, methodology, and measurement issues. The fourth section statistically tests my hypotheses and investigates the results, while considering further implications with respect to certain violation cases. Finally, the last section draws some conclusions.

\section{Literature Review and Hypotheses}

This section reviews previous work on alliance termination, which will aid in the generation of relevant hypotheses. The main focus of this study, external security factors, is taken up, with the rest of the discussion and hypotheses to follow.

\section{EXTERNAL SECURITY LEVELS AND THREATS}

The primary question of this study is this: Under what external security conditions do states terminate alliances by violation? As noted previously, CAM provided the operational construct for understanding alliance termination. According to Holsti's (1973) comprehensive survey of alliance studies, the most frequently cited hypothesis for alliance termination was that "alliance cohesion depends on external danger and declines as the threat is reduced." 4 In fact, alliances often disintegrate after the external threats dissipate. The Grand Alliance formed during World War II dissolved after the threat by the Axis powers had disappeared. Earlier, the Triple Entente had ended upon the close of hostilities following World War I. That historically alliances have been contingent on the presumption of threat (or lack thereof) has presumably corroborated the validity of CAM.

However, as some IR scholars have suggested, this is not the prevalent manner of alliance termination. Inasmuch as I can observe cases of termination by violation - the main focus of this study - can numerous cases be uncovered in which states terminated alliances by violation only when their external security deteriorated? For example, Italy and Romania exited the Triple Alliance and joined World War I against Germany and Austria-Hungary, its former allies. As a second example, in the face of the growing threat by Nazi Germany, France allowed Germany to annex Czech territory under the Munich Agreement in 1938, against its defense

4. As is frequently cited, right after the Berlin Wall fell, John Mearsheimer (1990) predicted NATO would not work properly in the absence of the Soviet threat. Furthermore, in November 1990, Kenneth Waltz argued that "NATO is a disappearing thing. It is a question of how long it is going to remain as a significant institution even though its name may linger on" (quoted in RISSE-KAPPEN 1997, 220). 
pact with Czechoslovakia. With the abundance of counter-examples that refute CAM, in conjunction with weak (or no) statistical evidence (BENNETT 1997; LEEDS 2007), the previously predominant model of alliance termination is found wanting.

The next question is this: Why is CAM irrelevant to some alliance termination cases and what limits its explanatory power? A simple answer is the difficulty in sharing the external threats among alliance members. Although CAM is premised on the fact that an alliance will endure as long as external threats exist, the existing alliance does not guarantee that members will continue to share the same sense of threat and to see merit in the alliance. Even if a shared sense of threat exists, threat levels often vary among members due to national capacities, policy orientations, and geographical factors, such as contiguity. ${ }^{5}$ Actually, this is problematic not just for CAM, but also for other approaches to alliance studies. For instance, the economic theory of alliances, which characterizes deterrence as a pure collective good (OlsON and ZecKHAUSER 1966) and the subsequent joint public models (see SANDLER 1993, amongst others), treat external threats as exogenous factors but do not provide a sufficient explanation as to the asymmetric nature of external threats to alliance members (SANDLER 1993, 468-72). Considering threat asymmetries across members, the estimation of individual realignment behavior under the assumption of shared external threats to the alliance as an aggregated unit is untenable.

So what then is an alternative explanation to CAM, that is, what links external security factors to alliance termination by violation? My approach to this puzzle is to focus on individual states and their external security environment. Research in the 198 os shows promise in its theorizing on the microfoundations of state realignment behaviors. Under the state-as-utility-maximizer assumption, BERKowitz (1983) presents a model of state realignment in thirty-six international treaty organizations (гтоs) and tests it by comparing the expected utility within and outside itos. ALtFELD (1984) develops Berkowitz's model and treats state realignment policy as a constrained optimization problem and suggests that the marginal utility of an alliance theoretically should be negative when states intend to improve their security by exiting their alliance. ${ }^{6}$ IUSI-SCARborough

5. In this regard, it is suggestive that Holsti (1973) puts certain qualifications on the CAM hypothesis, especially from the viewpoint of the degree of threat felt by each alliance member. See Chapter 1, "International Alliances: A Survey of Theories and Propositions," 16-18 and 24-26.

6. The conditions for alliance dissolution are presented in Altfeld $(1984,528)$. 
and Bueno de Mesquita (1988) also evaluate state realignment behavior under external security threats. Focusing on the costliness of alliances with endangered states, they show empirically that terminating risky alliances is a convenient way for states to improve their own security in the presence of imminent threats, which they define as a "Fine Weather Relationship."7 Contra earlier scholarship, they find that alliances are more likely to terminate when external security threats to states (and especially to its allies) exist. Thus, this literature has not only helped redirect inquiry into alliance cohesion, but is novel in two primary ways: (1) empirical research on alliance formation/termination was conducted on the theoretical grounds of a rational unitary actor approach; and (2) realignment behavior is understood as strategic unilateral action for improving a state's security; therefore, the unit of analysis is not an alliance as a whole, but the individual state.

More recent work by IR theorists (Fearon 1997; Morrow 1991; SMith $1995 ; 1996 ; 1998)$ on alliance formation, commitment, and reliability provides clear guidance for the violation problem. One of the main findings is that alliance formation and maintenance is a form of costly signaling to honor alliance commitments. Of note, SмIтH $(1995 ; 1996)$ examines alliance reliability during wars and finds that it tends to be underestimated because of selection bias: states with unreliable alliances are more likely to be attacked than those with reliable ones, and consequently, alliances are relatively more reliable at war than previously appreciated. Alliance violation in the face of imminent external threats is inseparable from alliance reliability, which is precisely the focus of this study, i.e. in the context of termination. The presence of external threats may induce states to violate alliance commitments, which then triggers alliance dissolution. The relationship between alliance fragility and external threats requires attention in order to investigate alliance termination by violation.

So if this causal claim is valid, why do states abrogate alliances under imminent extreme threats? What are the states' objectives in premature alliance termination? States can break costly alliances by abandoning threatened "friends," as in Iusi-Scarborough and Bueno de Mesquita (1988), or desperate states can abandon the status quo by adopting a more aggressive policy stance. In the latter case, states may attack their allies in violation of alliance commitments, nonaggression pacts, or entente. However, I leave

7. For detailed empirical results, refer to IUSI-SCARborough and BUENo DE MESQUiTA (1988, 90-93). 
this discussion for a later section and will reflect upon it in light of my empirical results.

Hypothesis 1: The lower a state's security level is, the more likely

it will be to violate the alliance.

Hypothesis 2: The more external security threats a state experiences, the more likely it will be to violate the alliance.

\section{Capability Change and Asymmetric Alliance}

As Altfeld (1984) and Morrow (1991; 1993) show, there is a tradeoff between alliance formation and a build-up of armaments as a means of improving a state's security conditions. Altreld (1984) specifies the state's utility function for alliance formation versus armament build-up, which sets the equilibrium condition therein. Extending the utility theory of alliance and armaments, Morrow $(1991 ; 1993)$ views the tradeoff between autonomy and security as an alternative to the capability aggregation model. Morrow tests the hypotheses that: (1) changes in individual states' capabilities tend to result in alliance termination, because this change alters the balance between autonomy and security in an alliance; and (2) asymmetric alliances are easier to form and survive longer than symmetric ones due to the stability of the tradeoff between autonomy and security.

In a series of comprehensive tests on alliance duration performed by BENNETT (1997), the capability change hypothesis is strongly supported, while the asymmetry hypothesis is not. LAKE (1999), too, does not find statistically significant support for the tradeoff model with respect to U.S. alliance policy. On the other hand, LeEDS and SAVUn's (2007) findings demonstrate robust support for Morrow's (1991; 1993) model and his attendant empirical results. My study revisits these hypotheses to test Morrow's model anew. In addition, I test the tradeoffs between autonomy and security to validate the proposition that increased national capability is expected to cause alliance violation. Here, the purpose is to determine whether using a different unit of analysis would influence the empirical results in such a manner as to confirm or refute these previous analyses.

Hypothesis 3: If a member state's capabilities increase, the state will be more likely to terminate the alliance by violation.

Hypothesis 4: If a member state's capabilities change drastically, the state will be more likely to terminate the alliance by violation.

Hypothesis 4': If an alliance is power-asymmetric, the alliance will be less likely to be terminated by violation. 


\section{Domestic Politics}

Do domestic institutions matter for alliance duration, especially with regard to termination by violation? Are democracies more likely to comply with their alliance commitments? Do changes in domestic regimes or governments impair alliance compliance? Previous research on the relationship between domestic political factors and alliance reliability and duration has provided an assortment of responses to these questions.

The broad-based consensus in the previous literature is that democratic alliances are longer-lived than non-democratic ones (BENNETT 1997; Gaubatz 1996; LaI and ReIter 2000; LeedS 2007). To illustrate the commitment problem in democracy, MARTIN (2000) discusses credibility in international commitments with regard to the democratic ratification process in the United States. However, GartzKe and Gleditsch (2004) suggest that democracies are less reliable allies in credible intervention in wartime due to information costs in policymaking, the advantages of interest groups, and the periodic turnover of governments. Hence, this article will consider whether and how the domestic polity affects alliance termination by violation.

Next, regime changes tend to produce shifts in alliances regardless of whether they are externally imposed, the result of internal revolution, or nonviolent (SIVERSON and STARR 1994). Since their argument does not specify types of alliance shifts in the face of domestic regime change, this study will shed light on whether regime change causes alliance termination by violation. In this regard, not only regime change, but also a change in leadership should be examined in accordance with the "Selectorate Theory" put forth by Bueno De Mesquita et al. (2005), which focuses on political leaders in office. For example, after William Gladstone won the election to become Prime Minister of the U.K. and took office in 1880, he changed the Turkish policy and withdrew from their defense pact. ${ }^{8}$ Most often, regime change entails a change in leadership or change in government but not vice versa. A dedicated test on change in leadership is necessary, since regime change is relatively rare and expected to cause greater political turbulence than a leadership change. Therefore, it is reasonable to assume that, in the midst of political turbulence and instability, a state with a new regime might behave differently and employ a different realignment policy than a state with a new leader under a preexisting regime.

8. ATOP ID 1330. 
Hypothesis 5: If an alliance member is a democracy, it will be less likely to abrogate the alliance.

Hypothesis 5': If a state experiences a regime change in a given year, the state will be more likely to abrogate the alliance.

Hypothesis 5": If a state experiences a change in leadership in a given year, it will be more likely to abrogate the alliance.

\section{Formation of Outside Alliances}

The formation of a new alliance can replace the existing alliance. In theory, if a new alliance is effective enough for a state and the costs for replacing the old alliance instead are negligible or less onerous, then this is an expedient strategy to improve, if not ensure, one's security climate. LEEDS and SAVUN (2007) demonstrate that this observation has empirical support. Anecdotally, Germany under Bismarck in the late nineteenth century provides an example where the terms of the alliance's relationships were in constant flux. On the other hand, such a replacement strategy can be costly due to lengthy negotiations with possible allies and the potential for a decline in reputation with respect to equivocation over alliance policy in the long run.

H6: An alliance is more likely to be terminated when its members form a new outside alliance.

\section{Wartime and Peacetime Alliances}

Wartime alliances, which are alliances formed during wartime for at least one member, ${ }^{9}$ are considered temporary because the casus foederis of wartime alliances tend to disappear after the war ends. Because of the short-lived nature of wartime alliances and the possibility that different mechanisms drive alliance duration, some authors, such as SIVERSON and STARR (1994) and Morrow (1991), drop wartime alliances from their empirical tests. BENNETT (1997) includes them in his tests and finds that they negatively affect the alliance duration period. On the other hand, in terms of violation of wartime alliances, it might be assumed that this factor might have a weaker impact on a states' violation, as the casus foederis clearly exists for the allies, and they do not have much incentive to deviate from the agreement during wartime. Thus, the last hypothesis is presented below:

Hypothesis 7: Wartime alliances are generally more short-lived than peacetime alliances; however, this tendency is relatively weak in termination cases by violation.

9. The Aтор Codebook, pages 15-16. 


\section{Research Design}

The previous section presented the argument that higher external threats can lead states to break alliances, which is an alternative hypothesis to CAM. I also generated a set of supplemental hypotheses on alliance violation following the previous work that took an individual state approach to alliance duration, which is a crucial component of this article. This section lays out how I will test the above hypotheses and why I will adopt such methods. I begin with my sample data (of alliances), and then I elaborate on the quantitative model for analysis and variable measurement.

\section{SAMPLE DATA}

The alliance data comes from the most recent version of the ATOP dataset (v3.o), which includes 648 alliances from 1815 to 2003. The temporal and spatial domains in this study are alliances in the European region from 1815 to 2000 . The region includes the European countries (1815-2000), the United States (1898-2000), Turkey (1914-2000), Japan (1895-1945), and China (1950-2000), as discussed in Bueno de Mesquita (1981, 95-98). All alliances are included, except for six ${ }^{10}$ which include alliances by a mixture of countries in the European region and others, either bilateral or multilateral, which are eliminated because their targets and purposes are obviously not relevant to the European region.

There are three reasons for limiting the sample population to the European region. First, the region has a large but still manageable number of alliances (338) for analysis, and about $59.8 \%$ of all the alliances in the latest ATOP dataset include European alliances. Second, the data necessary to assess national security levels and capability change are primarily available for European and related countries during the period. Third, and related to the second point, it is easier to observe the interactions and strategic dynamism of European countries because of their contiguity and density. Thus, the exclusive focus on the region provides a viable and sufficient sample of alliances to perform my tests.

Given the sample of alliances, I use state-year data (ATOP3_OsY) in the ATOP dataset, since I set the state-year in each alliance as the unit of analysis. The dates of entry and exit are coded in the data as Leeds and SAVUN have explained in detail $(2007,1123-24)$. As noted earlier, some work in the 1980 os used the individual state approach to study states' realignment behaviors, while more recent work by Morrow (1991), Bennet T (1997),

10. ATOP IDs are 2550, 2555, 3180, 3740, 4220, and 4400. They are regarded as alliances in the European region although they include some countries from other regions. 
and LeEDS and SAVUn (2007) has adopted the alliance approach to better observe alliance duration and the institutional aspects therein. Since the objective here is to observe state-level violations, the alliance itself is not a suitable unit of analysis; therefore, I exclusively focus on individual violations both in bilateral and multilateral alliances. In general, across the study of alliance termination, both approaches have certain advantages, as well as drawbacks, and there is no simple solution to the unit-of-analysis problem. Thus, revisiting the approach used in the 198 os will provide a good opportunity for discussing this problem, which is endemic to the study of alliance dynamics. A synthesized approach to complement one another is necessary, though it will be reserved for future research.

This "state approach" raises the problem of an appropriate definition for alliance termination. Early withdrawal from an alliance and actual alliance termination are different and should be treated as such. Simply put, in the case of bilateral alliances, a state's withdrawal from the alliance is classified as alliance termination. However, in a multilateral framework, a state's withdrawal from the alliance may not necessarily signify alliance termination. Fortunately, in the dataset used here, 44 out of the 62 multilateral alliances $(72.1 \%)$ terminate with mutual agreement by all the parties involved, and only 18 alliances have so-called halfway dropouts for any reason during their alliance periods. Given that there are 338 alliances in the sample population, and that this study focuses on individual alliance violation, the definition problem is trivial.

The next step is to classify modes of alliance termination so that I may identify the conditions under which a state departs the alliance. In the ATOP data, LEEDs et al. (2002) classify six termination modes: fulfillment, renegotiation/replacement, violation, exogenous loss of sovereignty, disappearance of specified casus foederis, and loss of war. ${ }^{11}$ This classification is useful for determining not only when an alliance ends, but also how it ends, because different mechanisms are expected to drive each termination mode.

In light of the objective in this study, let me briefly elaborate upon these termination modes. First, they have a wide spectrum that encompasses the degree of autonomy with which a state can terminate alliances. Regarding "termination by violation," for instance, an obvious violator has a higher degree of autonomy in its decision-making, while other allies do not, especially when the violation instantly brings about alliance dissolution. In this mode, I expect that the conditions behind alliance violation will be more visible and observable if the variables are measured properly. On the other 
hand, "external loss of sovereignty" and then "loss of war" are ranked as the least voluntary modes of alliance termination both for the state and others. In the middle of these voluntary and involuntary terminations, I find "disappearance of specified casus foederis" and "fulfillment." However, the processes leading to termination differ from one another because states can passively await alliance fulfillment, while "disappearance of specified casus foederis" is voluntary termination by the parties upon a relevant agreement after the raison dêtre of an alliance ceases to exist. Especially given that the latter termination mode was mostly brought about by victory in war, the study of this particular mode might be equivalent to the study of successful alliances in defeating or containing enemies. ${ }^{12}$ Lastly, renewal/renegotiation sometimes entails a change of membership, alliance obligations, or institutional structure in a given alliance but does not signify its termination.

The descriptions of each mode suggest that the focus on alliance violation is a good starting point for the study of alliance termination, given its relative observability of violation in comparison to the other modes. As for the other termination modes, though I include them for the estimation of alliance violation using the competing-risk event-history model, I do not conduct empirical tests on them. Theorizing and verifying causal mechanisms of other termination modes will form a possible agenda for future research, as LEEDS and SAVUN (2007, 1130) suggest.

STATISTICAL MODEL

To differentiate between different termination modes, while specifically focusing on alliance violation, I follow LeEDS and SAVUN (2007) in using the competing-risks event-history model because it enables us to analyze not only when an alliance ends, but how it ends. In this model, each observation is exposed to the risks of experiencing the different modes of termination, and if each state-year experiences a failure, the observation ends. Also, as the purpose of this article is to focus on alliance termination by violation among the different modes, the failure due to risks other than violation (such as fulfillment or exogenous loss of sovereignty) is treated

12. LEEDS and SAVUN (2007) actually include the disappearance of specified casus foederis in the fulfillment mode. However, these two modes could be governed by different causal mechanisms as argued above, and it may be better to separate them (see, for example, the Grand Alliance in World War II, the Triple Entente in World War I, and the defense pact among Britain, France, and Sweden during the Crimean War). 
as right-censored. Thus, with this model, I will specifically analyze when a state terminates an alliance by violation.

Two assumptions must be met for this model to work (Box-STEFFENSMEIER and JONES 2004, 166-69). The first assumption is that the risks of the different termination modes are conditionally independent. For example, the survival times for the risk of violation, ceteris paribus, are independent of the survival times for the risk of fulfillment. Strictly speaking, this might be a strong assumption in some cases, such as the risks of termination by loss of war and exogenous loss of sovereignty, where these risks are expected to be related to each other. However, the assumption of conditional independence with respect to the risks of violation vis-à-vis the others is justifiable, considering its relationship with the other termination modes. The second assumption, though theoretical, is that any of the possible modes of termination could have occurred if the duration of observation had been long enough. As long as the above assumptions hold, this competing-risk event-history model will be useful in the analysis of alliance termination by the different modes.

One of the most important steps in event history analysis is the choice of models. If I knew the distribution of the risk-specific hazard rates, I could perform a test with a specific parametric model. However, given the fact that the distribution is unspecified, it is risky to make such a strong assumption regarding its distribution (BOX-STEFFENSMEIER and JONES 2004, 16669). The alternative is to use a semi-parametric model, which only specifies the functional form for the influence of covariates but leaves the shape of the risk-specific hazard rates as unspecified as possible. Consequently, following LEEDS and SAVUN's (2007) work, I use the Cox proportional hazards model for the following tests, though I obtain nonparametric estimates for the impact of certain time-constant variables, such as alliance obligation and wartime alliance (LEEDS and SAVUN 2007, 1126).

MEASUREMENT OF VARIABLES

\section{Dependent Variable:}

For each state-year in an alliance, if a state terminates an alliance by violation, the unit is coded as 1. Otherwise (i.e., no failure or non-violator), it is coded as o. Also, if an alliance is terminated by the other five modes (i.e., fulfillment, renegotiation/replacement, exogenous loss of sovereignty, disappearance of specified casus foederis, and loss of war), it is treated as censored and coded as o. If an alliance did not fail until December 31, 2000, the end point of the observations, it is considered censored and also coded as o. This data is based on the state-year data in the ATOP dataset. 


\section{Independent Variables:}

Security Level: To test hypothesis 1, I evaluate the impact of national security levels on alliance violation. The EUGene predictions of the dispute outcome expected (game equilibrium) is given in the International Interaction game developed in Bueno de Mesquita and Lalman (1992), which forms the basis for the "Expected Utility Theory of War." I use actual security levels for each state-year in Europe (SeurTact) for this variable. ${ }^{13}$

External Security Threats: External threats are one of the most elusive concepts in the international security literature, though a number of IR scholars have devised ways to measure it quantitatively. However, there is no established consensus as to the measurement of external threats, and existing methods are not without drawbacks or free from manipulation. Therefore, I return to the simple but precise way to measure threat levels that individual states confront by using the Militarized Interstate Disputes (MIDs v3.10) data in the cow project to evaluate hypothesis 2 . The first one (MIDS_Number) is the sum of the number of MIDs that a country has experienced in a given year. The second one (MID_Ave_Host_Lev) is the average of hostility levels in a given year. A hostility level is coded from 1 (lowest) to 5 (highest) and if there is no MID, I code the hostility level as o. It is preferable to use them together because the sum of MIDs represents the frequency of MIDs, and a hostility level represents the intensity of MIDs.

Capability Change: This variable is evaluated using the latest National Military Capabilities (NMC v3.02) variable, also in the cow project. First, I use the Composite Index of National Capability (CINC) score (leaving it unchanged), which combines six indexes to measure national capabilities. With this index, then, I generate the variable (Cap_Change) from the absolute value of the change rate from year $t-1$ to $t$ and give a numerical value to each unit. This measurement is preferable to coding bivariate values based on capability change from the year of alliance formation because it captures more updated national capability changes and has less arbitrariness in variable generation. ${ }^{14}$

Power Asymmetry: This is a dummy variable (PwrAsymm) coded 1 for an asymmetric alliance, and o for a symmetric alliance. This coding is based on the designation of major power states in the cow project. For example, if alliance members are all major powers or minor powers, the

13. See Bennett and Stam (200oa; 200ob). In the applied context, they use EUGene (BenNetT 1997).

14. Although LEEDS and SAVUN (2007) used the latter measurement, I return to the simpler coding methods by BenNetT (1997) and Morrow (1991). 
alliance is coded o. If they are a mixture of major and minor power states, the alliance is coded 1. I followed Morrow (1991) and LeEDS and SAVUn's (2007) operationalization.

Types of Alliance Obligations: Types of alliance commitments/obligations (Sstype), as defined by Singer and Small $(1966 ; 1969)$, are coded in the cow alliance dataset: Defense pacts are coded as 1, neutrality and nonaggression pacts as 2, and ententes as 3 . However, every type of alliance obligation, not the highest degree of obligation, is separately coded in the ATOP data. This study recodes the ATOP data following Singer and SMALL $(1966 ; 1969)$ to assess the influence of the degree of obligation on alliance violation. Therefore, the variable (ATOP_SStype) is coded to reflect the highest degree of obligation in an alliance (Defense or Offense-1, Neutral or Nonaggression-2, Consultation/Entente-3).

Wartime: Wartime is a dummy variable coded 1 if any member of the alliance was a participant in a war, according to the Correlates of War data on interstate wars (version 3.0), at the time the alliance was initially formed. ${ }^{15}$

Democratic member: To test the relationship between democracies and alliance violation, I use the variable polity2 (Revised Combined Polity Score: from -10 [autocracy] to +10 [democracy] from the 2009 Polity IV dataset constructed by by Monty G. Marshall and Keith JAGgers (2002).

Polity Change: I generate this variable (Polity_change) from the absolute value of change from year $t-1$ to $t$ in the polity 2 data and give a numerical value to each unit.

Leader Change: This dummy variable is coded 1 for a change in leadership in a given state-year, and o for no change. This variable is constructed from the leader data in the "Logic of Political Survival Data Source," by Bruce Bueno de Mesquita, Alastair Smith, Randolph Siverson, and James Morrow. ${ }^{16}$

Formation of New Outside Alliances: This is a dummy variable (NewAlliance) that is coded 1 if a state forms other alliances in a given state-year; otherwise, it is coded o.

\section{Results and Analysis}

This section discusses the results of the empirical tests for the hypotheses presented earlier. The results are shown on the next page in the table. I briefly analyze the effects of each variable in light of my hypotheses.

15. ATOP Codebook, page 34.

16. See http://www.nyu.edu/gsas/dept/politics/data/bdm2s2/Logic.htm (accessed 15 March 2008). 
With respect to external security threats, this hypothesis is strongly supported, since both the sum and hostility level of MIDs are positive and significant. This shows that states are more likely to terminate an alliance by violation in the face of increasing external threats, not a decline in threats. ${ }^{17}$ For external security levels, unfortunately, the hypothesis does not receive significant support, although the coefficient on SeurTact is negative, which is in accordance with our expectations. Despite the weak influence of this variable, the results suggest that alliance termination by violation tends to occur in international crises. Put differently, alliance violation might be part and parcel of an opportunistic strategy for a state to improve its security environment.

All the variables on national capabilities support MorRow's (1991; 1993) hypotheses. The significant results for these variables imply that capability change, including an arms build-up, reshapes the balance between security and autonomy and enables states to break alliances at will. The other side of the coin is that asymmetric alliances are less affected by rapid capability changes and likely to be stable, as Morrow concludes. Notably, these empirical results lend credence to those hypotheses that are based on individual states' violations, contra Morrow and other scholars (BENNETT 1997; LEEDS and SAVUN 2007) who treat an alliance as an aggregated unit. This replication of Morrow's analysis consequently lends additional support for the contention that relationships exist between national capabilities and state realignment behavior.

On the other hand, the results indicate that the domestic politics hypotheses are unsupported, contrary to our expectations with respect to the previous work. I also conducted tests for only bilateral and only multilateral alliances, and these show almost identical results as those displayed in the table for the polity and regime change variables; therefore, this empirical test fails to demonstrate that democracies are less likely to dishonor alliance obligations, nor that regime change leads to alliance violation. Only a change in leadership receives support at the $5 \%$ level of significance. These results illustrate that domestic institutional and/or political factors have less of an impact on a state's realignment decisions.

17. I also find strong support for the external security threat hypothesis in the test for the pooled termination mode, which includes endogenous termination by states (violation, fulfillment, and the disappearance of casus foederis), but treats exogenous termination modes (loss of sovereignty and loss of a war) and renegotiation/renewal as censored. This result shows the potential for generalization of the relationship between alliance termination and increased external threats in future research. 
TABle 1. Cox Proportional Hazard Estimates of alliance termination by violation (independent competing risks).

\section{Variable}

Estimated Coefficient (Standard Error)

\section{External Security}

SeurTact

MID number

MID hostility level

$$
\begin{aligned}
& -.0016(.0044) \\
& .1587^{* * *}(.0274) \\
& .3095^{* * *}(.0698)
\end{aligned}
$$

\section{National Capability}

Cap change

Power Asymmetry

$$
\begin{gathered}
.8845^{* * *}(.1595) \\
-.6740^{\star * \star}(.2019) \\
4.3772^{* * *}(1.1904)
\end{gathered}
$$$$
\text { Cap }
$$

\section{Domestic Determinants}

$$
\begin{aligned}
& \text { polity2 } \\
& \text { polity change } \\
& \text { leader change }
\end{aligned}
$$

$$
\begin{aligned}
& -.0034(.0142) \\
& .0564(.0393) \\
& .3557^{* *}(.2168)
\end{aligned}
$$

\section{Others}

Wartime

Atop SStype

$.4232(.2635)$

New alliance

Observation Points

Notes: ${ }^{\star} \mathrm{p}<0.1 ;{ }^{* *} \mathrm{p}<0.5 ;{ }^{* *} \mathrm{p}<0.01$.

\# Robust standard errors in parentheses. (They are calculated with the assumption of potential non-independence among cases in the same alliance.)

\#\# The basic model with the above estimates includes Cap_change and polity2. Due to multicollinearity, variables that are highly correlated, such as (1) Cap_change and Cap and (2) polity2, polity_change, and leader_change, are estimated interchangeably.

\#\#\# I also estimated only bilateral and multilateral alliances, and the results are almost identical. I omitted them due to space limitations. 
Alternatively, I may conclude that the causal mechanism that drives alliance termination by violation is mostly governed by external security and national capability factors, not by domestic political ones.

Next, I will briefly review the results of my other variables. The coefficient on the formation of new outside alliances is significant at the $5 \%$ level. However, additional work is required, because this dummy variable captures each state-year experiencing any outside alliance formation but is not specified in terms of the new alliance's objectives and potential enemies. If a new alliance is expected to replace the old one, this specification is necessary to refine our estimates. However, it is possible that such a variable would weaken these results.

Wartime alliances are short-lived, as expected. According to the Kaplan-Meier Survival Estimate for the pooled termination mode, the incidence rate (failure rate) for wartime alliances is almost five times that of peacetime alliances. ${ }^{18}$ If I narrow the focus to termination only by violation, however, the incidence rate itself becomes lower and the difference between wartime and peacetime becomes less clear. ${ }^{19}$ The results in the table (i.e., Cox Proportional Hazard Estimates) also indicate that wartime is not significant. Thus, as I hypothesized, wartime alliances are shortlived, but this tendency becomes weaker in termination-by-violation cases. At first glance, this result might be puzzling, but it is a reasonable conclusion, given that the objective of wartime alliances, and cooperation for the containment of hostile states, is evident to all parties at the time of alliance formation. As long as the common objective is shared, there is little incentive to break the alliance.

The type of alliance obligation does not achieve a conventional level of statistical significance. In fact, the degree of alliance obligation does not represent the order of incidence rates in sequence. ${ }^{20}$ In other words, nonaggression and neutral pacts are the most likely to endure, whereas consultation pacts and/or ententes are the least likely to do so. Surprisingly,

18. For the pooled termination mode, refer to the previous footnote. The incidence rates are 0.000369 for wartime and 0.0000736 for peacetime, and these estimates are significant at less than $0.01 \%$ on both Log-rank and Wilcoxon tests. See Appendix A for the graph.

19. The incidence rates are 0.0000801 for wartime and 0.00003 for peacetime. The significant rates are $0.02 \%$ for the Log-Rank test and 3\% for the Wilcoxon test. See Appendix B for the graph.

20. In the Kaplan-Meier Survival Estimate, the incidence rates are .0000364 for defense and offense pacts, $6.35 \mathrm{e}-06$ for neutral or nonaggression pacts, and .0000982 for consultation pacts; these estimates are significant at the $0.1 \%$ level on Log-rank and at the $1 \%$ level on Wilcoxon tests. 
defense or offense pacts, which entail the deepest obligations, are in the middle of the two categories. If I drop nonaggression and neutral pacts as in LEEDS and SAVUN (2007), this variable enters the equation positively and significantly at the $5 \%$ level without affecting the other results. Therefore, quoad hoc, the deeper the alliance obligation is, the less likely it is that the members will break their alliances.

Having discussed my findings thus far, I now return to the main issue of this study, external security and alliance violation. The remaining question is why states opportunistically break their alliances in the presence of external security threats. Admittedly, the frequency and intensity of MIDs might bias the parameter, given the incredible difficulty in measuring threats to a state. However, in the absence of a precise measurement for threats-one for which there is a consensus in the literature-this simple method still captures the relationship between a state's alliance violation and the heightened international tensions that the state confronts.

Both theoretically and empirically, some possible explanations exist for alliance violation in the face of imminent threats. First, "fine weather friendships" account for some alliance break-up cases, as suggested by Iusi-Scarborough and Bueno de Mesquita (1988): states whose allies are severely threatened and have experienced a series of escalated MIDS, particularly because of their allies, are more likely to abandon their allies. ${ }^{21}$ In other words, under increased external threats, egoistic self-preservation, instead of altruism, will prevail for states, which in turn facilitates alliance violation.

This kind of alliance violation historically has been especially prevalent in small threatened states. For instance, the Balkan Pact was abrogated in 1940 when Italy invaded Greece through Albania. Whereas this was a defense and consultation pact, other allies (Yugoslavia, Romania, and Turkey) did not assist Greece. Moreover, in violation of the bilateral nonaggression pact between Romania and Greece, Romania supported Germany to aid Italy in the invasion of Greece and Yugoslavia in 1941. As in the annexation of Czechoslovakia in 1938, great powers may abandon the threatened buffer state to improve their own security conditions. In fact, we often see a state's shift to a disengagement policy even if the security threat to the state is not so imminent as to affect its survival. By withdrawing from the alliance commitment, the state intends to avoid possible costs and risks associated with the existing agreement. For example, in

21. For their empirical findings, see IUSI-SCARborough and BUENo DE MESQUita (1988, 90-93). 
1897 , Britain indicated that it would not continue its support for the Mediterranean entente, comprised at that time of Britain, Italy, and AustriaHungary, because the defense of Constantinople, formerly of strategic importance, was "an antiquated standpoint." 22

The second explanation is that a state's policy shift toward war initiation often occurs against the backdrop of acute circumstances. States attack allies or others in violation of the alliance agreements, thereby altering the status quo with respect to their security conditions. There are a plethora of such cases of bellicosity across history. In 1913, Bulgaria, unsatisfied with its territorial spoils in the First Balkan War, provoked war with Serbia and Greece, despite its defense treaties with them. Japan unilaterally occupied Manchuria in 1931 against its consultation pact with France, the United States, and the United Kingdom. Germany's invasion of the Soviet Union in 1941, and the Soviet Union's attack on Japan in 1945, are also examples of such alliance violations that result from a state's policy shifts in the wake of a crisis. ${ }^{23}$

Thus, we have different paths from the same variable (security threat) to the same outcome (alliance termination by violation). Of course, these paths to violation are just two possibilities among many, and I do not exclude the possibility of other paths that lead to alliance violation. This is a foray into a complex set of mechanisms, and further refinement of these arguments in future research will contribute to a deeper understanding of state realignment behavior in the presence of external threats. In this sense, my ambiguous results, with respect to external security levels, might suggest that a variety of state reactions is possible.

\section{Conclusions}

This study has endeavored to shed light on the relationship between external security factors and realignment behavior by individual states. It has demonstrated that increased external threats lead to alliance termination by violation, which is contradictory to the predictions of CAM. Also, I presented two possible processes leading up to alliance violation under heightened international tensions. The results pertaining to security factors are robust in the presence of plausible rival arguments, especially the tradeoff between security and autonomy, and the capability change model proposed by Morrow (1991). On the other hand, the effects of domestic political institutions and regime change were not statistically significant

\footnotetext{
22. ATOP ID 2330, 2215, 2140/2365, and 1360, respectively; see TAYLOR $(1954,369)$.

23. ATOP ID 1470, 1475, 2095, 2470, and 2525, respectively.
} 
and only a change in leadership had the expected impact on alliance violation. Unlike previous work on alliance duration, my empirical tests suggest that alliance termination by violation is less affected by pure domestic politics but is more vulnerable to international security conditions and national capabilities, such as the build-up of arms.

Possible extensions to this study also fall in the field of alliance termination. First, given the fact that imminent external threats tend to produce alliance violations, IR scholars should further explore explicit models/ theories of alliance termination by violation under a variety of security conditions. Second, to complement Morrow's (1991) model on capability change as an alternative to CAM, possible models/theories should be tested to contribute to our understanding of alliance termination, in general, beyond the issue of alliance violation. To further examine this issue, however, improvements to both the concept and measurement of external security threats are necessary. Lastly, this study, as well as LeEDs and SAVUN (2007), speak to the necessity of investigation of other termination modes, since they are expected to undergo different causal processes leading to their termination. Building upon the empirical study of alliance termination by violation, systematic research into the ATOP dataset classifications would be beneficial to the study of alliance termination more broadly.

\section{REFERENCES}

Altfeld, Michael F.

1984 "The Decision to Ally: A Theory and Test." Western Political Quarterly 37(4): 523-44.

Altfeld, Michael F., and Bruce Bueno de Mesquita

1979 “Choosing Sides in Wars." International Studies Quarterly 23(1): 87-112.

BenNetT, D. Scott

1997 “Testing Alternative Models of Alliance Duration, 1816-1984." American Journal of Political Science 41(3): 846-78.

Bennett, D. Scott, and Allan C. Stam

2000a "EUGene: A Conceptual Manual." International Interactions 26(2): 179204.

2000 "A Universal Test of an Expected Utility Theory of War." International Studies Quarterly 44(3): 451-80. 
Berkowitz, Bruce D.

1983 "Realignment in International Treaty Organizations." International Studies Quarterly 27(1): 77-96.

Box-STEFFEnSMEIER, Janet M., and Bradford S. Jones

2004 Event History Modeling: A Guide for Social Scientists. New York: Cambridge University Press.

Bueno de Mesquita, Bruce

1981 The War Trap. New Haven: Yale University Press.

Bueno de Mesquita, Bruce, and David Lalman

1992 War and Reason: Domestic and International Imperatives. New Haven: Yale University Press.

Bueno de Mesquita, Bruce, Alastair Smith, Randolph M. Siverson, and James D. Morrow

2005 The Logic of Political Survival. Cambridge, MA: MIT Press.

FEARON, James D.

1997 "Signaling Foreign Policy Interests: Tying Hands Versus Sinking Costs." Journal of Conflict Resolution 41(1): 68-90.

GARTZKe, Erik, and Kristian Skrede Gleditsch

2004 "Why Democracies May Actually Be Less Reliable Allies." American Journal of Political Science 48(4): 775-95.

Gaubatz, Kurt Taylor

1996 “Democratic States and Commitment in International Relations." International Organization 50(1): 109-39.

Holsti, Ole R., P. Terrence Hopmann, and John D. Sullivan

1973 Unity and Disintegration in International Alliances: Comparative Studies. New York: Wiley.

Iusi-ScArborough, Grace E., and Bruce Bueno De Mesquita

1988 “Threat and Alignment Behavior." International Interactions 14: 85-93.

LAI, Brian, and Dan ReITER

2000 "Democracy, Political Similarity, and International Alliances 18161992." Journal of Conict Resolution 44(2): 203-27.

LAKE, David A.

1999 Entangling Relations: American Foreign Policy in Its Century. Princeton, NJ: Princeton University Press.

Lalman, David, and David Newman

1991 “Alliance Formation and National Security." International Interactions 16: $239-53$.

LEEDs, Brett Ashley

2003 "Alliance Reliability in Times of War: Explaining State Decisions to Violate Treaties." International Organization 57(4): 801-27. 
LeEds, Brett Ashley, and Burcu SAvun

2007 “Terminating Alliances: Why Do States Abrogate Agreements?" Journal of Politics 69 (4): 1118-32.

Leeds, Brett Ashley, Jeffrey M. Ritter, Sara McLaughlin Mitchell, and Andrew G. LoNG

2002 "Alliance Treaty Obligations and Provisions, 1815-1944." International Interactions 28: 237-6o. See also http://atop.rice.edu/.

Marshall, Monty G., and Keith Jaggers

2002 Polity IV Project: Dataset Users' Manual. College Park: University of Maryland.

Mearsheimer, John J.

1990 "Back to the Future: Instability in Europe after the Cold War." International Security 15(1): 5-56.

Morrow, James D.

1991 "Alliances and Asymmetry: Alternative to the Capability Aggregation Model of Alliances." American Journal of Political Science 35(4): 904-33.

1993 "Arms Versus Allies: Tradeoffs in the Search for Security." International Organization 47(2): 207-33.

1994 "Alliances, Credibility, and Peacetime Costs." Journal of Conflict Resolution 38(2): 270-97.

Olson, Mancur, Jr., and Richard Zeckhauser

1966 "An Economic Theory of Alliances." Review of Economics and Statistics 48(3): $266-79$.

REED, William

1997 "Alliance Duration and Democracy: An Extension and Cross-Validation of 'Democratic States and Commitment in International Relations." American Journal of Political Science 41(3): 1072-78.

Risse-Kappen, Thomas

1997 Cooperation Among Democracies: The European Influence on U.S. Foreign Policy. Princeton, NJ: Princeton University Press.

SANDLER, Todd

1993 "The Economic Theory of Alliances: A Survey." Journal of Conflict Resolution 37(3): 446-83.

Singer, J. David, and Melvin SMall

1966 "Formal Alliances, 1815-1939." Journal of Peace Research 3: 1-31.

Siverson, Randolph M., and Harvey StarR

1994 "Regime Change and the Restructuring of Alliances." American Journal of Political Science 38(1): 145-61.

Small, Melvin, and J. David SINGER

1969 "Formal Alliances, 1815-1965: An Extension of the Basic Data." Journal of Peace Research 6: 257-82. 
SMiтh, Alastair

1995 “Alliance Formation and War." International Studies Quarterly 39(4): 405-25.

1996 “To Intervene or Not to Intervene: A Biased Decision.” Journal of Conflict Resolution 40(1): 16-40.

1998 "Extended Deterrence and Alliance Formation." International Interactions 24: 315-43.

1999 "Testing Theories of Strategic Choice: The Example of Crisis Escalation." American Journal of Political Science 43(4): 1254-83.

SNyDER, Glenn H.

1997 Alliance Politics. Ithaca, NY: Cornell University Press.

TAYLOR, A. J.

1954 The Struggle for Mastery in Europe, 1848-1918. Oxford: Clarendon Press.

WALT, Stephen M.

1987 The Origins of Alliances. Ithaca, NY: Cornell University Press.

1997 "Why Alliances Endure or Collapse." Survival 39(1): 156-79.

WALTz, Kenneth

1979 Theory of International Politics. Reading, MA: Addison-Wesley Pub. Co. 


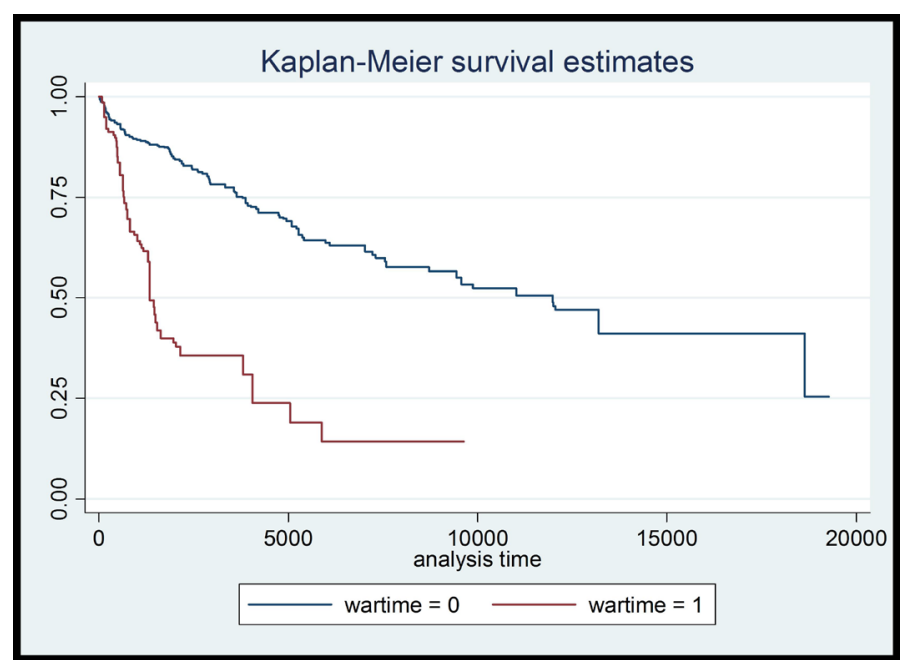

APPEndix A. Pooled Termination Mode.

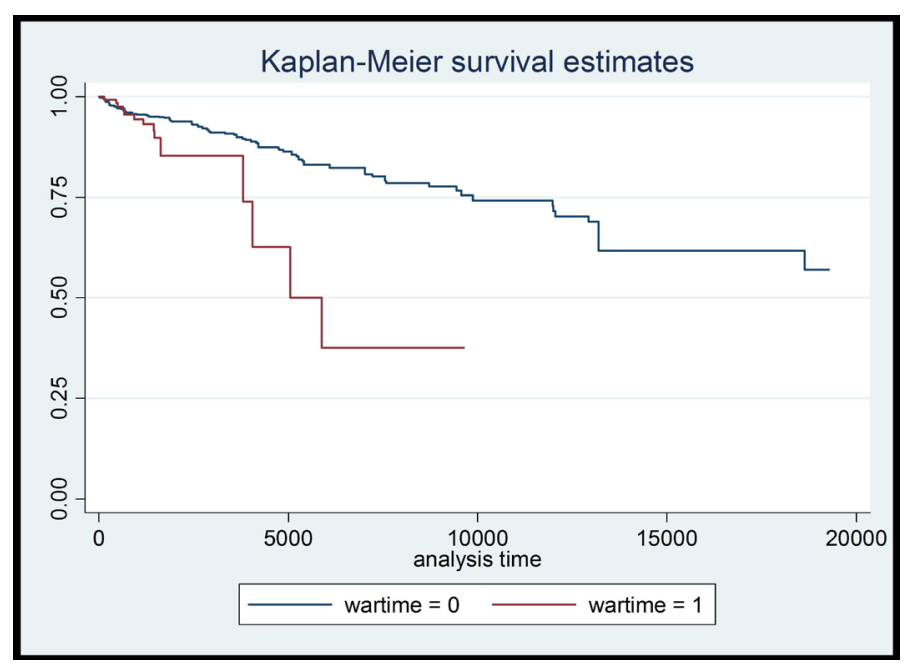

APPENDIX B. Termination by Violation Only. 